\title{
Muito Além De Wakanda: um estudo acerca dos aspectos cultural e identitário no filme Pantera Negra ${ }^{1}$
}

\author{
Mucho más allá de Wakanda: un estudio de los aspectosculturales y de \\ identidad en la película pantera negra \\ Beyond Wakanda: A Study About The Cutural And Identity Aspects In \\ Black Panther
}

\author{
Wesley Guilherme Idelfoncio de Vasconcelos ${ }^{2}$ \\ Daywson Adler Freires de Sousa ${ }^{3}$ \\ Ricardo Rigaud Salmmito ${ }^{4}$
}

\begin{abstract}
Resumo
O presente artigo tem por objetivo analisar o filme Pantera Negra, do diretor norte-americano Ryan Coogler, que foi lançado no mês de fevereiro ano de 2018 no Brasil pela Marvel Studios e Walt Disney Pictures. Tal produto audiovisual será examinado no tocante aos aspectos cultural e identitário, sobre a ótica antropológica e cinematográfica. O trabalho, a partir de uma metodologia de cunho bibliográfico, juntamente com a análise do conteúdo da obra, buscará observar relações entre a construção dos personagens e do mundo fictício de Wakanda tendo com os temas citados acima, bem como suas implicações dentro do mundo ficcional e fora dele a metodologia de análise fílmica é baseada nos estudos da professora Manuela Penafria. Serão abordados conceitos e autores tais como Durval Muniz, Peter Burke e Michel Serres, para que através de seus estudos sobre identidade e cultura este artigo consiga elucidar seus leitores acerca do objeto de estudo selecionado. Além destes temas, o trabalho analisará as relações existentes entre antropologia, cinema e cultura, abordando autores como Walter Benjamin, Roque Laraia e Andréa Barbosa, visando assim uma melhor construção de sua análise bem como um aprofundamento necessário para o melhor entendimento do seu objeto de estudo.
\end{abstract}

Palavras-Chave: Antropologia; Cinematografia; Cultura; Identidade; Pantera Negra;

\section{Resumen}

Este artículo tiene como objetivo analizar la película pantera negra, del director estadounidense Ryan Coogler, que fue lanzado em febrero año de 2018 em Brasil por Marvel Studios y Walt Disney Pictures. Este producto audiovisual se examinará em relación con los aspectos culturales y de identidad, sobre la óptica antropológica y cinematográfica. La obra, basada em uma metodologia bibliográfica, junto com el análisis del contenido de la obra, tratará de observar las relaciones entre la construcción de los personajes y el mundo ficticio de Wakanda com los

\footnotetext{
${ }^{1}$ Artigo submetido à RELACult - Revista Latino-Americana de Estudos em Cultura e Sociedade.

2 Graduando em Jornalismo; Universidade Federal do Cariri; Juazeiro do Norte, Ceará, Brasil; wesleyguilherme1998@gmail.com

3 Graduando em Jornalismo; Universidade Federal do Cariri; Juazeiro do Norte, Ceará, Brasil; adlerssousa@gmail.com
}

\footnotetext{
${ }^{4}$ Mestre em Comunicação e Cultura Contemporânea; Universidade Federal do Cariri; Juazeiro do Norte, Ceará, Brasil; ricardo.salmito@ufca.edu.br
} 
temas citados anteriormente, como sus implicaciones Dentro del mundo ficticio y fuera de ella la metodologia del análisis cinematográfico se basa en los estudios de la profesora Manuela Penafria. Discutiremos conceptos y autores como Durval Muniz, Peter Burke y Michel Serres, para que a través de sus estudios sobre identidad y cultura este artículo pueda elucidar a sus lectores sobre el objeto de estudio seleccionado. Además de estos temas, el trabajo analizará las relaciones existentes entre la antropologia, el cine y la cultura, dirigiéndose a autores como Walter Benjamin, Roque Laraia y Andréa Barbosa, com el objetivo de construir mejor su análisis, así como uma necesaria profundización Para la mejor comprensión de su objeto de estudio.

Palabras claves: Antropología; Cinematografía; Cultura; Identidad; Pantera negra;

\begin{abstract}
This article aims to analyze the film Pantera Negra, by the American director Ryan Coogler, which was released in February year of 2018 in Brazil by Marvel Studios and Walt Disney Pictures. Such audiovisual product will be examined regarding cultural and identity aspects, on anthropological and cinematographic optics. The work, based on a bibliographical methodology, together with the analysis of the content of the work, will seek to observe relations between the construction of the characters and the fictional world of Wakanda with the topics cited above, as well as its implications Within the fictional world and outside it the methodology of film analysis is based on the studies of Professor Manuela Penafria. We will discuss concepts and authors such as Durval Muniz, Peter Burke and Michel Serres, so that through their studies on identity and culture this article can elucigive their readers about the selected object of study. In addition to these themes, the work will analyze the existing relations between anthropology, cinema and culture, addressing authors such as Walter Benjamin, Roque Laraia and Andréa Barbosa, aiming to better construct their analysis as well as a necessary deepening for the best understanding of their object of study.
\end{abstract}

Keywords: Anthropology; Cinematography; Culture; Identity; Black Panther;

\title{
1. Introdução
}

A antropologia, ao estudar o homem e o comportamento relacionado à sua cultura e manifestações culturais dentro de seus grupos de convivência e socialização, acata o cinema como ferramenta para melhor realização dessa tarefa. A relação entre antropologia e cultura é ampla e converge em vários pontos, o estudo dos costumes dos homens e o estudo do homem por ele mesmo são, em sua essência, convergentes. Segundo Tylor (apud LARAIA, 2009) “a maior realização da Antropologia no começo do século XX foi a ampliação e a clarificação do conceito de cultura."

A própria definição de cultura, proposta por Durval Muniz (2007) carrega em si um toque antropológico, segundo o professor,

o que chamamos de cultura, conceito que por seu uso no singular já demonstra sua prisão à lógica da identidade é, na verdade um conjunto múltiplo e multidirecional de fluxos de sentido, de matérias e formas de expressão que circulam permanentemente, que nunca respeitaram fronteiras, que sempre carregam em si a potência do diferente, do criativo, do inventivo, da irrupção, do acasalamento. $\mathrm{Na}$ verdade, nunca temos cultura: temos trajetórias culturais, fluxos culturais, relações culturais, redes culturais, conexões culturais, conflitos, lutas culturais. (MUNIZ, 2007) 
No que diz respeito à chamada "potência do diferente", pode-se estabelecer uma relação com o conceito de alteridade, que é um dos termos chave para se estudar antropologia e culturas. Ver o outro como diferente e perceber o estranhamento ao se deparar com isso, estranhamento esse sem a carga negativa do significado da palavra.

Os registros cinematográficos entram no contexto pôr, no desenvolvimento das principais pesquisas etnográficas do século $\mathrm{XX}$, terem sido considerados como instrumentos científicos, tanto quanto o microscópio, capazes de ampliar o olhar do cientista, pois ao "estabilizar" ou "fixar" os dados obtidos em campo facilitariam análises posteriores (BARBOSA, 2000). A partir disso, o presente trabalho objetiva realizar uma análise de cunho exploratório através de bibliografias relacionadas a esses três campos, antropologia, cultura e cinema, este, aqui representado por autores como Gérard Betton em sua obra intitulada Estética do Cinema (1987) e também a partir do próprio objeto de estudo, que será o filme Pantera Negra.

Lançado no começo do ano de 2018, o filme conta a história de T'Challa e do reino fictício de Wakanda, localizado no continente africano. Após a morte de seu pai e antigo rei, T'Chaka, o personagem principal deve retornar a seu país para assumir o trono, bem como o manto do Pantera Negra, espírito protetor de Wakanda e seu povo. Entretanto, T’challa começa a questionar as responsabilidades que agora recaem sobre si, ao mesmo tempo que um antigo inimigo do reino é localizado e deve ser punido.

Indo muito além da mera dramaturgia heroica cinematográfica, o filme permite uma leitura acerca da identidade e cultura Wakandiana, que têm diferentes percepções pelo seu povo e pelo povo que habita as outras nações do mundo. Se utilizando de autores como Michel Serres, Durval Muniz e Peter Burke, o presente trabalho busca analisar a problemática da identidade associada à cultura no filme Pantera Negra, aguçando o olhar para o mundo fictício construído e suas implicações no mundo que se encontra fora das telas.

\section{A Relação Entre Cinema, Antropologia e Cultura}

O cinema pode ser definido como, antes de mais nada, uma arte, um espetáculo artístico. É também uma linguagem estética, poética ou musical - com uma sintaxe e um estilo; é uma escrita figurativa, e ainda uma leitura, um meio de comunicar pensamentos, veicular ideias e exprimir sentimentos. Uma forma de expressão tão ampla quanto outras linguagens, bastante elaborada e específica. Fazer um filme é organizar uma série de elementos espetaculares a fim de proporcionar uma visão estética, objetiva, subjetiva ou poética do mundo. (BETTON, 1987) 
As produções cinematográficas se configuram como meios de comunicação de massa por serem, a seu modo, acessíveis à um grande e diversificado público e por serem, estimuladores do desenvolvimento de determinada ideologia, foi por esta finalidade que as produções cinematográficas da Alemanha foram tão incentivadas no período nazista, por exemplo. Exerciam determinado grau de influência sobre quem assistia, de modo que a ideologia do partido era mais facilmente absorvida. No caso do cinema, todas as técnicas de produção, efeitos e o realismo exagerado não permite a reflexão das audiências devido a velocidade deste tempo, os indivíduos apenas assimilam todos os conteúdos transmitidos sem objeção alguma. A utilização de estrelas de cinema e de televisão para publicidade facilita imenso esta tarefa os media, visto que a maioria dos indivíduos alienados deseja conseguir uma vida como a de determinada estrela de cinema ou de televisão. (ADORNO; HORKHEIMER; 1985)

Mas as opiniões divergem, segundo Walter Benjamin

A descrição cinematográfica da realidade é para o homem moderno infinitamente mais significativa que a pictórica, porque ela lhe oferece o que temos o direito de exigir da arte: um aspecto da realidade livre de qualquer manipulação pelos aparelhos, precisamente graças ao procedimento de penetrar, com os aparelhos, no âmago da realidade (BENJAMIN, 1994).

Mesmo com opiniões divergentes com relação ao seu papel para com a sociedade, na configuração de meio comunicacional, o cinema pode ser caracterizado como um instrumento metodológico para a antropologia, capaz de captar algo semelhante ao olhar antropológico. Assim facilitando a análise etnográfica a partir dos conjuntos de imagens registradas, captar algo que passou despercebido em uma primeira análise, antes realizada por meio de diários de bordo dos pesquisadores, como foi o caso de Bronislaw Malinovski no seu trabalho mais conhecido chamado Os Argonautas do Pacífico Ocidental (1978). No trabalho em questão, o antropólogo se utilizou de seu diário de campo e de fotografias dos nativos estudados para a elaboração e desenvolvimento de seu trabalho etnográfico.

Desde o nascimento da linguagem e da disciplina até os dias de hoje, muitas foram as aproximações. Uma delas tem sido no sentido de compreender as relações entre a produção imagética de uma sociedade e sua própria vida social. Sem cair ingenuamente no engano de considerar o cinema como espelho da vida, procura-se caminhos para desvendar essa complexa relação entre arte e vida. O cinema é um artefato cultural. Artefato cuidadosamente manufaturado, buscando propiciar ao seu público um misto de identificação e distanciamento. O filme carrega, desde sua concepção até sua exibição pública, intenções e cargas simbólicas 
que são oferecidas ao espectador que as degusta conforme suas próprias intenções e competências simbólicas. (BARBOSA, 2000). Diversas óticas assistindo ao mesmo filme produzem diversas leituras, afinal, a capacidade ideológica das pessoas varia conforme sua bagagem cultural.

A história da construção da linguagem fotográfica e cinematográfica desenvolveu-se paralelamente à elaboração dos métodos clássicos da antropologia. Houve muitas aproximações ao longo dessa história, mas, de forma geral, elas expressaram formas de olhar e de construir problemas de maneira homóloga - uma colaboração ao mesmo tempo distante e provocadora, mas que evidencia o quanto a antropologia, a fotografia e o cinema, enquanto construções culturais, podem compartilhar o desafio de entender e significar o mundo e sua diversidade. (BARBOSA, 2006).

O cinema foi, durante boa parte do século passado, introduzido, relacionado e usado como instrumento para o desenvolvimento de diversos trabalhos etnográficos, como, por exemplo, os de Mead e Bateson nas ilhas de Nova-Guiné. A etnografia que, segundo Hoebel (2006) consiste no estudo descritivo das sociedades humanas. [...] a maior parte do trabalho etnográfico é realizada por antropólogos treinados que estudaram profundamente as técnicas de observadores-participantes, as quais exigem observações e entrevistas, objetivas e penetrantes, relação empática com um povo, e relatório minucioso. A chegada do cinema e sua relação com a etnografia residem nos enquadramentos dados à determinadas cenas e comportamentos retratados, e também por possibilitar o registro da cultura gravada.

A antropóloga Margaret Mead realizou muitos trabalhos utilizando-se de fotografias e do filmagens como instrumento para tal, segundo ela a objetividade dos registros fotográficos e fílmicos era suporte para a preservação de registros das expressões visuais de padrões culturais que estariam fadados à extinção. Seria tarefa da antropologia dar a conhecer, estudar e produzir registros das culturas de todo o mundo antes que elas viessem a desaparecer, e, nesse sentido, a fotografia e o cinema, considerados em seu aspecto técnico, se configuram como instrumentos poderosos. (MEAD apud BARBOSA, 2006)

A relação entre cinema, antropologia e cultura, como acima explanado, é notável e inter relacionada. Em vários pontos os três se relacionam e estabelecem ligações significativas, como é o caso da antropologia e da cultura, o cinema, pode ser definido, dentre outras conotações, como um instrumento que acrescenta detalhes e minimiza os obstáculos existentes em sua ausência. O filme Pantera Negra traz a tona um debate sobre vários conceitos relacionados à cultura e antropologia. A partir do recorte realizado para a produção dessa pesquisa, pode-se destacar conceitos como o de hibridismo, contraglobalização, pertencimento, alteridade, 
identidade, etnocentrismo, realizar um contraponto entre a tradição e a modernidade e também promover reflexões sobre aspectos figurativos da sociedade wakandiana apresentada no filme.

\section{Metodologia}

A metodologia aplicada no trabalho consiste no estudo do conteúdo do filme e na realização da análise entre a produção audiovisual, relacionando com conceitos antropológicos, comunicacionais e outros que acordem com os estudos sobre a cultura, como, por exemplo, os de alteridade, etnografia, contraglobalização, diglossia cultural, identidade, pertencimento e comunicação - nesse caso, o processo e o campo de estudo.

A pesquisa com sondagem de conteúdo envolve análise das mensagens, dos enunciados dos discursos e da busca do significado dessas mensagens, as linguagens, a expressão verbal, os enunciados, são vistos como indicadores significativos, indispensáveis para a compreensão dos problemas ligados às práticas humanas e a seus componentes psicossociais. (SEVERINO, 2007). Neste artigo, será realizada uma observação do filme em questão a partir de uma perspectiva de compreensão de suas linguagens e nuances éticas e comportamentais, além de uma análise dos personagens principais, contextos socioculturais e as relações que podem ser estabelecidas entre determinadas partes do filme e conceitos propostos pelos autores aqui citados.

É também uma análise do longa-metragem através da mensagem proporcionada ao telespectador. Segundo Manuela Penafria (2009), doutora em ciências da comunicação com especialização em cinema, em seu trabalho intitulado Análise de filmes - conceitos $e$ metodologia(s)

a análise de filmes é a decomposição do mesmo de uma forma que não se trata de construir outro filme, mas fomentar uma ligação entre os elementos apresentados a fim de interpretá-los. Embora existam alguns tipos de análises de filmes, como por exemplo: Análise textual, análise poética. (PENAFRIA, 2009)

O presente apresenta um estudo de conteúdo cujo tipo, ainda segundo a autora, se dá por meio de relatos acerca do tema do filme. A finalidade do mesmo é realizada através de relatos condizentes com o tema, finalizando com a sua decomposição para entender as temáticas abordadas e estabelecer ligação com os conceitos determinados a partir de recortes específicos do longa-metragem. O presente estudo ainda conta, para o estabelecimento da relação entre os campos, com uma pesquisa de caráter bibliográfico, que se caracteriza como aquela realizada a partir do registro disponível, decorrente de pesquisas anteriores, em documentos impressos, como livros, artigos, teses etc. Utiliza-se de dados ou de categorias teóricas já trabalhadas por 
outros pesquisadores e devidamente registrados. Os textos tornam-se fontes dos temas a serem pesquisados. O pesquisador trabalha a partir das contribuições dos autores dos estudos analíticos constantes dos textos. (SEVERINO, 2007)

\section{Wakanda, Identidade e Cultura}

O filme Pantera Negra, da Marvel Studios e Walt Disney Pictures, apresenta a história do país fictício de Wakanda, localizado no continente Africano. Para todas as nações do mundo, Wakanda é apenas mais um país subdesenvolvido e atrasado culturalmente, socialmente e politicamente. O que a maioria dos indivíduos não sabe é que, na verdade, o país é uma superpotência tecnológica, lar das maiores reservas da terra de um metal altamente resistente e raro chamado vibranium, que possibilitou ao seu povo desenvolvimento tecnológico e econômico. Com medo de que, se revelarem a verdadeira natureza e situação de seu país para o mundo, acabariam por perder seu "estilo de vida", os wakandianos (aqueles que nascem em Wakanda) decidem continuar com o segredo acerca de sua realidade.

É interessante observar, em primeiro lugar, a visão que o resto do mundo tem acerca de Wakanda, que os cega sobre sua verdadeira realidade. Para o autor Michel Serres (s/d), tal erro ocorre quando os indivíduos confundem a identidade de alguém com os seus pertencimentos. Pertencimentos, segundo o autor, são sempre plurais; dizem a respeito sobre coletivos dos quais você faz parte. Já a identidade diz respeito à singularidade; aquilo que torna os seres diferentes. Dessa forma, no filme Pantera Negra, os indivíduos enxergam os wakandianos sob a ótica de serem habitantes de um país subdesenvolvido, como se esta fosse sua identidade, sem perceber todas as nuances que se escondem nesta atitude de envelopamento. Sob uma ótica antropológica, a rotulação de Wakanda como mais um país pobre do continente africano se constitui, a seu modo, como uma postura etnocentrista, afinal, segundo Franz Boas (apud HOEBEL; FROST; 2006) "A humanidade é uma. As civilizações muitas."

A construção da identidade dos personagens no filme é também passível de análise. Por exemplo, a irmã do protagonista, Shuri, além de princesa de Wakanda é também extremamente habilidosa com a tecnologia, sendo ela a responsável pela construção do traje feito de vibranium usado pelo seu irmão quando este assume a identidade do Pantera Negra. Sua identidade é construída pelo conjunto de pertencimentos. Para Michel Serres (s/d, p.01) “[...] O que redunda em reduzir a pessoa a uma categoria ou o indivíduo a um coletivo. Não, você só faz parte de tal país, de tal religião ou de sexo. Originam-se daí tantas desgraças para o mundo que é melhor corrigir este erro". 
Outro ponto de observação no filme deve ser a questão de como o povo de Wakanda olha para o restante do mundo. Ao seu ver, a revelação da verdade sobre o país levaria o ao colapso, pois as outras nações iriam querer guerrear pelo vibranium, bem como iriam destruir o 'modo de vida wankandiano'. O medo da influência externa pode ser observado nos estudos do historiador Peter Burke (2003) que, em sua obra, aponta que na atual conjuntura de globalização, nenhuma cultura pode se isolar do restante do mundo. Dado este fato, que segundo o autor é irreversível, restam-se alguns cenários possíveis para o futuro das culturas do mundo. No caso da população de Wakanda, pelo menos no tocante à esse medo, esse futuro possível parece estar próximo do cenário chamado de "contraglobalização", que é a aversão a formas globais de cultura; o medo à invasão de culturas estranhas e sua influência, que podem ser 'fatais' para a destruição da cultura local, que é considerada 'pura'.

Entretanto, o que os wakandianos não percebem é que o objetivo de se manterem distantes do mundo não poder ser concretizado. Para Burke (2003, p. 105) "Em outras palavras, é uma reação forte mas que pode não durar muito. A resistência está fadada ao fracasso no sentido de que os objetivos daqueles que fazem parte da resistência, deter a marcha da história ou trazer de volta o passado, são intangíveis".

Ainda analisando proteção ao externo pregada pelos wakandianos quanto a sua cultura, podemos perceber que esta está impregnada de noções de preservação de uma identidade local, que é baseada em sua exclusão do mundo exterior. Para o autor Durval Muniz (2007), não temos uma 'cultura', no singular; temos fluxos culturais, que se transformam e fluem de acordo com diferentes fatores. Não podemos congelar uma cultura e isolá-la, pois "Em qualquer sociedade humana, o que caracteriza as produções culturais sempre foi as misturas, as mestiçagens, os hibridismos, as dominações, as hegemonias, as trocas, as antropofagias, as relações enfim" (MUNIZ, 2007, p.16).

No filme também percebemos que os wakandianos, em suas práticas e ações cotidianas, demonstram receber influências de diversas áreas e povos; preservando costumes de seus antepassados mas trazendo novas interações para o seu meio. Isso fica claro quando notamos que, por exemplo, para T'challa assumir o trono de Wakanda, após a morte de seu pai, ele deve passar pela cerimônia de coroação no local conhecido como as "Águas do Guerreiro", em que deve lutar contra qualquer um que tenha uma reivindicação forte para o trono, como forma de provar seu valor como guerreiro e líder. Mas que, em outros momentos do filme, T'challa visita Shuri em seu laboratório, cheio de armas e inventos tecnológicos. Voltando para os cenários propostos por Peter Burke (2007) podemos notar nesta parte do filme uma ligação com a "hibridização cultural", esfera em que há uma mistura de dois fluxos culturais. Neste âmbito, 
práticas são assimiladas pela cultura em destaque, cristalizadas como se fossem pertencentes a ela e naturalizadas, para posteriormente serem defendidas. Não há homogeneização; há um híbrido das duas culturas conflitantes.

Dessa forma, podemos perceber como a identidade é associada à cultura na produção cinematográfica por seus personagens, sejam aqueles que vivem em Wakanda ou aqueles que a observam exteriormente, sem perceberem as problemáticas que tal visão acarreta.

\title{
As Relações Antropológicas presentes no Filme
}

Ao falar sobre a preocupação dos povos em relação à diversidade de modos de comportamento existentes entre os diferentes povos, o professor Roque Laraia (2009) cita Heródoto, historiador grego, num episódio onde ele analisava o sistema social dos lícios, o grego dizia que

\begin{abstract}
Eles têm um costume singular pelo qual diferem de todas as nações do mundo. Tomam o nome da mãe e não o do pai. Pergunte-se a um lício quem é, e ele responde dando o seu próprio nome e o de sua mãe, e assim por diante, na linha feminina. Além disso, se uma mulher livre desposa um homem escravo, seus filhos são cidadãos integrais; mas se um homem livre desposa uma mulher estrangeira, ou vive com uma concubina, embora ele seja a primeira pessoa do Estado, os filhos não terão qualquer direito à cidadania. (HERÓDOTO apud LARAIA, 2007)
\end{abstract}

Em seguida, o professor relata sobre quão etnocentrista foi a afirmação "diferem de todas as nações do mundo" visto que para tal afirmação, o historiador se baseou na própria cultura. Em seguida, Laraia traz uma afirmação de Heródoto que, teoricamente, renega sua postura

\footnotetext{
Se oferecêssemos aos homens a escolha de todos os costumes do mundo, aqueles que lhes parecessem melhor, eles examinariam a totalidade e acabariam preferindo os seus próprios costumes, tão convencidos estão de que são melhores do que todos os outros. (HERÓDOTO apud LARAIA, 2007)
}

O objetivo da inclusão dessas duas passagens nesse tópico é para realizar a introdução do conceito de etnocentrismo, que é um dos aspectos antropológicos mais presentes na obra fílmica. Entretanto, a produção do longa foi muito detalhista no que diz respeito à antropologia cultural. Para se analisar uma construção cultural e, no caso, a representação de uma cultura pelo cinema, parte-se de alguns pontos-base, que são o visual (cenários, objetos, vestimentas), costumes (religião, valores, crenças), linguagem (gírias, cumprimentos, vocabulário), expressões artísticas (danças, literatura, música e arte) e história (mitos, acontecimentos importantes). (FARIAS, 2018) 
No que se refere ao etnocentrismo, podemos ilustrar com duas cenas do filme, ainda no começo quando, no noticiário, Wakanda é retratada como um país pobre da África. O segundo momento é no final do filme, quando o rei T'Challa resolve ajudar os outros países utilizandose de seus recursos e acaba arrancando risadas irônicas de outros representantes de países, que, pelo personagem ser de um país da África Equatorial, é automaticamente relacionado com a pobreza e miséria quando, na verdade, o rei T'Challa é o personagem mais rico dos quadrinhos, devido às minas de Vibranium, a fortuna do Pantera Negra ultrapassa os 500 bilhões de dólares. (CAMPOS, 2018)

Com relação aos pontos chave para análise antropológica de uma cultura, tem-se exemplos de cada um deles no filme. Os visuais podem ser representados pela configuração de Wakanda, por ser uma cidade isolada do mundo, as construções se diferem de outros lugares, não sofrem influência do meio externo, assim como as vestimentas, que são diferenciadas e, por isso, características da cultura retratada.

Os costumes também foram representados fidedignamente, antropologicamente falando, por exemplo, tem-se os rituais wakandianos, como o de passagem, onde o novo rei luta com qualquer membro do reino que se ache melhor pretendente ao trono, e também no ritual onde o novo governante assume o manto do Pantera Negra, e faz uma viagem astral até os seus antepassados, em uma versão wakandiana do Paraíso Cristão.

No tocante às expressões artísticas, tem-se a música de Wakanda, que é marcada por tambores fortes acompanhados de sonoros sons produzidos por todos que dela compartilham. As armaduras, roupas, acessórios e demais adornos do reino e da sociedade são um exemplo de expressões artísticas que podem ser consideradas como únicas por não sofrerem influências externas à África.

Por fim, tem-se a linguagem, que se configura como aspecto mais identitário de uma cultura, e que, no filme, mesmo a grande maioria dos diálogos sejam em inglês, percebe-se uma variação na pronúncia, semelhante ao dialeto normalmente falado na região sul do continente africano. Outra marca característica é a saudação, onde os wakandianos cruzam os braços sobre o peitoral, seguidos de um sonoro e forte "Wakanda forever". A língua, por ser a forma como o homem organiza o mundo onde se insere, encerra em si o espírito de um povo, e só o estudo das línguas permitirá o acesso às especificidades culturais de cada comunidade. "As forças e fraquezas de uma língua são determinadas não pelo que pode ser expresso nela, mas pelas ideias que ela própria inspira em virtude de sua própria vitalidade interior. A verdadeira medida de uma língua está na sua clareza, precisão, e vividez das ideias que inspira na nação a qual pertence, através de cujo intelecto se formou e no qual tem por seu turno uma influência 
formativa (...). Toda a língua deve ser entendida do ponto de vista do sentido que a nação lhe doou, e não a partir de um ponto de vista estranho." (FIDALGO; GRANDIM; 2005)

\section{Considerações finais}

O filme Pantera Negra, sendo trazido para fora das telas dos cinemas, nos faz refletir acerca das noções que temos sobre determinadas culturas e povos. No filme, a nação fictícia de Wakanda não é nada do que a maioria do mundo acredita. Ao contrário, é a nação mais desenvolvida tecnologicamente do mundo e uma das mais ricas. Quantas vezes não nos surpreendemos quando imergimos em fluxos culturais diferentes dos quais estamos habituados? Nossos preconceitos nos limitam, e a lógica da identidade cultural nos aprisiona.

Por se tratar de uma obra audiovisual recente, não há muitas bibliografias específicas sobre o filme, porém, os textos utilizados como base, nos foram úteis para o esclarecimento dos conceitos propostos inicialmente, com suas problematizações e relações entre filme e realidade, antropologia e cultura.

Sendo assim, o presente trabalho, ao abordar a identidade cultural por uma perspectiva antropológica e cinematográfica no tocante à obra estudada, espera suscitar nos indivíduos questionamentos que possibilitem engrandecer sua visão de mundo acerca dos fluxos culturais que coexistem.

\section{Referências}

ADORNO, T.; HORKHEIMER, M. A Indústria Cultural: O Esclarecimento Como Mistificação das Massas. In: Dialética do Esclarecimento: Fragmentos Filosóficos. Zahar. Rio de Janeiro, 1987.

ALBUQUERQUE JÚNIOR, D. M.. Fragmentos do discurso Cultural: por uma análise crítica do discurso sobre a cultura no Brasil. In: NUSSBAUMER, Gisele Marchiori (Org.). Teorias e políticas da cultura: visões multidisciplinares. Salvador: EDUFBA, 2007.

. Fragmentos do discurso Cultural: por uma análise crítica do discurso sobre a cultura no Brasil. In: NUSSBAUMER, Gisele Marchiori (Org.). Teorias e políticas da cultura: visões multidisciplinares. P. 17. Salvador: EDUFBA, 2007.

BARBOSA, A.; CUNHA, E. T.. Antropologia e Imagem. Jorge Zahar Editor. p. 8. Rio de Janeiro. 2006.

Antropologia e Imagem. Jorge Zahar Editor. p. 13. Rio de Janeiro. 2006. Antropologia e Imagem. Jorge Zahar Editor. p. 30. Rio de Janeiro. 2006. 
BARBOSA, A. C. M. M. O Filme Dentro do Filme. Revista de Antropologia, USP. São Paulo, v. 43, n.1. p. 275-281, 2000.

BENJAMIN, W.. A obra de arte na era da sua reprodutibilidade técnica. In: Magia e técnica, arte e política: ensaios sobre a literatura e história da cultura. p. 187. Brasiliense. São Paulo, 1994.

BETTON, G.. Estética do Cinema. Martins Fontes. São Paulo, 1987.

. Estética do Cinema. Martins Fontes. p. 1. São Paulo, 1987.

BOAS, F. apud HOEBEL, E. A.; FROST, E. L. Antropologia Cultural e Social. Cultrix. p. 22. São Paulo. 2006.

BURKE, P. Hibridismo Cultural. São Lelpoldo. Editora Unisinos, 2003.

CAMPOS, G. Os 10 Mais Bilionários dos Quadrinhos. Portal ei Nerd! 2018 Disponível em <https://www.einerd.com.br/quadrinhos/os-10-mais-bilionarios-dos-quadrinhos/> Acesso em 26 de junho de 2018.

FARIAS, T. Pantera Negra e Antropologia Cultural. Portal Mente Insana Mente, 2018. Disponível em <http://menteinsanamente.16mb.com/pantera-negra-e-antropologia-cultural/> Acesso em 26 de junho de 2018.

FIDALGO, A.; GRANDIM, A. Manual de Semiótica. p. 57. Universidade da Beira Interior, Portugal, 2005.

HOEBEL, E. A.; FROST, E. L. Antropologia Cultural e Social. Cultrix. p. 8-9. São Paulo. 2006.

HERÓDOTO apud LARAIA, R. B. Cultura: um conceito antropológico. p. 10-11. Jorge Zahar. Rio de Janeiro, 2009.

. Cultura: um conceito antropológico. p. 11. Jorge Zahar. Rio de Janeiro, 2009.

LARAIA, R. B. Cultura: um conceito antropológico. Jorge Zahar. Rio de Janeiro, 2009.

MALINOVSKI, B. Os Argonautas do Pacífico Ocidental: um relato do empreendimento e da aventura dos nativos nos arquipélagos da Nova Guiné Melanésia. Abril Cultural. São Paulo, 1978.

PANTERA Negra. Direção: Ryan Coogler, Produção: Kevin Feige e David J. Grant. EUA. Marvel Studios, 2018, 1 DVD.

PENAFRIA, M. Análise de Filmes - conceitos e metodologia(s). VI Congresso SOPCOM, Universidade da Beira Interior, Portugal, 2009. Acesso em 21 de junho de 2018. Disponível em 〈http://www.bocc.ubi.pt/pag/bocc-penafria-analise.pdf>

SERRES, M. O que é identidade? Nota de Aula. S/d 
SEVERINO, A.J. . Metodologia do Trabalho Científico. - 121. ed. rev. e atual. - São Paulo: Cortez, 2007.

Cortez, 2007.

Metodologia do Trabalho Científico. p. 122- 23. ed. rev. e atual. - São Paulo:

TYLER apud LARAIA, R. B.. Cultura: um conceito antropológico. Jorge Zahar. p.27. Rio de Janeiro, 2009. 